archives

of thermodynamics

Vol. 37(2016), No. 1, 113-126

DOI: $10.1515 /$ aoter-2016-0008

\title{
Effectiveness of high temperature innovative geometry fixed ceramic matrix regenerators used in glass furnaces
}

\author{
GRZEGORZ WOŁKOWYCKI ${ }^{1}$
}

Bialystok University of Technology, Wiejska 45A, 15-351 Białystok

\begin{abstract}
The paper presents the effectiveness of waste heat recovery regenerators equipped with innovative ceramic matrix forming an integral part of a real glass furnace. The paper full description of the regenerators' matrix structure with its dimensions, thermo-physical properties and operating parameters is included experimentally determined was the effectiveness of the regenerators has been descrbed using the obtained experimental data such as the operating temperature, gas flows as well as the gases generated during the liquid glass manufacturing process. The effectiveness values refer not only to the heating cycle when the regenerator matrix is heated by combustion gases but also to the cooling cycle in which the matrix is cooled as a result of changes in the direction of the flowing gas. On the basis of the determined effectiveness values for both cycles and measurement uncertainties it was possible, to calculate the weighted average efficiency for each of the regenerators.
\end{abstract}

Keywords: Effectiveness matrix regenerators; Experimental results on effectiveness of regenerators

\section{Nomenclature}

\author{
$Q \quad-\quad$ heat, kJ \\ $t \quad-$ gas/air temperature, ${ }^{\circ} \mathrm{C}$ \\ $\overline{t_{1}^{\prime}} \quad-\quad$ average temperature of combustion gases of the inlet to the \\ regenerator while heating, ${ }^{\circ} \mathrm{C}$
}

\footnotetext{
${ }^{1}$ E-mail: g.wolkowycki@doktoranci.pb.edu.pl
} 


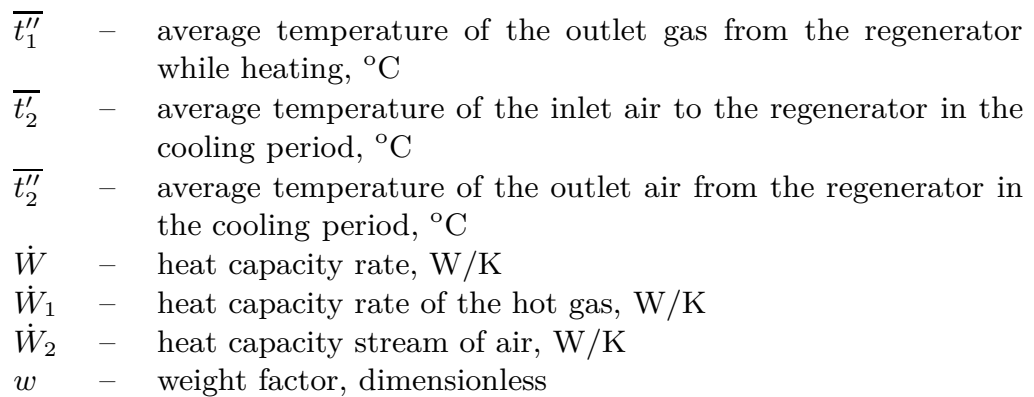

\section{Greek symbols}

$\varepsilon \quad-\quad$ regenerator heat transfer effectiveness

$\Delta-$ absolute uncertainty

$\tau \quad-\quad$ time period, $\mathrm{s}$

\section{Subscripts}

$1-$ regenerator matrix heating period

$2 \quad-\quad$ regenerator matrix cooling period

av $\quad-$ average value

$\max -\operatorname{maximum}$

min - minimum

\section{Introduction}

Regenerators used for the recovery of waste heat from the working space of industrial equipment such as furnaces, boilers, combustion turbine engines include a large group of heat exchangers. They are characterized by heat transfer from one type of energy medium to another by means of fixed matrix structures made either of ceramic bricks or other types of fittings of different shapes.

Among many others, the most significant classical contributions were made by [1] and [2]. Since that time regenerator modeling problems have attracted frequent attention of a number of researchers [3-6]. More recently a few papers have also been published on heat transfer phenomena in fixed matrix regenerators. Yu et al. [7] studied the performance of a fixed matrix regenerator made in the shape of a ball packed-bed designed for high temperature preheating of the air to be subsequently used for combustion. The scope of the research included experiments concerning pressure drop and numerical simulations of thermal characteristics of the bed. The main result of their research with respect to pressure drop was the creation of the friction factor for vertical gas flow across the bed. The proposed correlation used to determine the factor was expressed in terms of Reynolds number 
and porosity. The modeling applied to determine thermal characteristics consisted of differential energy balance equations for gas and matrix balls expressed using the heat transfer coefficient under forced convection transport. The results showed a dependency of both flue gas exit temperature and heat recovery non-dimensional parameter on the height of the bed.

In [8] presented was a model of energy transfer for a fixed bed regenerator filled with solid alumina spherical balls. Their model includes heat conduction in the matrix in the direction of gas flow and also convection transport in the gas. The experimental data presented in their work refer to the effectiveness that was compared to the results obtained from model equations solved by numerical analysis. Finally, the authors emphasized the need to develop a more accurate modeling of heat transport processes in regenerators. In turn, in their attempt to determine the heat transfer coefficient necessary for analysis of energy transport processes in fixed matrix regenerators [9] proposed was a 3D field model of coupled transfer of mass, momentum and energy in the form of a partial differential equations system. The model was solved using simulation software by Fluent Inc. The system refers to gas flow in regenerator channels of various geometry and takes into account both mixed convection heat transfer mode for the cooling period and also forced convection and radiation heat transfer coupled for the heating period. In their modeling they also used a low-Reynolds number model for turbulent transport under convection. To simulate thermal radiation under the hot period the discrete ordinates method was applied. The paper also presents the experimental set-up that makes it possible to conduct investigations of heat transport in a fixed matrix regenerator under hot conditions not like those that can occur in real scale apparatuses. Experimental results presenting the effectiveness of the fixed matrix regenerators have also been shown in [10].

In [11] developed was a mathematical model for performance analysis of glass furnace regenerators. Their modeling is based on mass and energy balances with the heat transfer rate determined as dependent on such factors as the regenerators surface area, heat transfer coefficient (modified after [12]) and log mean temperature difference between the streams of both air and flue gas. Other factors such as blockage by glass dust deposit, impact of the gas generated during glass melting process, losses across regenerator walls and leakage of air into the combustion gas are also considered. Additionally, a case study illustrating an application of the model is shown.

Despite that on regenerator problems many papers have been published 
so far there is very little experimental data on the effectiveness of fixed matrix regenerators of industrial scale working for high temperature applications, and hence, the objective of this paper is to fill this gap to some extent and present experimental data on effectiveness of the regenerators working with an industrial glass open hearth furnace under realistic operating conditions.

A description of waste heat recovery regenerators working integrally with an open hearth glass furnace in Bialystok Glass Works is presented. The regenerator chambers have been built of innovative geometry ceramic matrix not used in the glass industry before.

Another aim of the paper is to present experimental results obtained during normal operation of the entire system. On the basis of the procedure specified in this paper as well as the experimental temperature data heat capacities of gas flows and time individual period of operation, it was possible to determine the effectiveness of the regenerators. The effectiveness values were determined for both the heating and cooling periods. Due to the experimental nature of the research, measurement uncertainties of the analyzed parameters and also the resulting values of the effectiveness were indicated. The experimental results concerning the real object in 1:1 scale are unique and have not been described in the literature thus far.

\section{Construction of the glass furnace and regenerators}

Bialystok Glass Works makes use of an open hearth furnace operating continuously day and night. Approximately 6 tonnes of glass material is melted in order to produce lampshades. The furnace is built of the following parts: the melting chamber where glass raw material (batch) is melted, the manufacturing part for collecting primary material for further processing, the throat to enable the glass flow from the melting into the production chamber, batch port to feed glass raw material for melting, gas burners supplying GZ50 natural gas as fuel and two regenerators of identical shapes and same operating parameters for the recovery of waste heat. Figure 1 shows a schematic diagram of air and combustion gases flow during the operation of the whole system. 


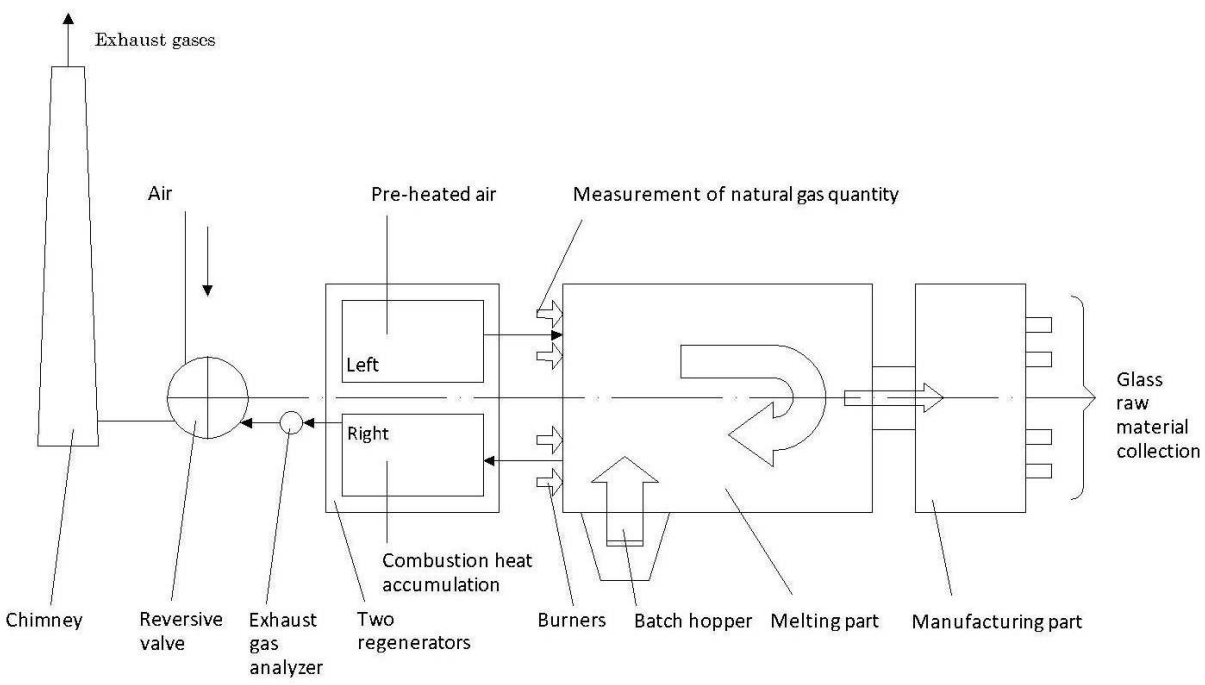

Figure 1: Schematic diagram of flow glass furnace.

\subsection{The regenerators}

Operational continuity and stability of glass furnace equipment normally requires two regenerators (right and left), which are located directly behind the melting chamber the glass furnace. The regenerators operate in a periodic manner. When one regenerator heats up, i.e., when it accumulates the heat resulting from the combustion process, the other regenerator is subjected to cooling, i.e., the process of giving out the accumulated heat into the air supplied for combustion. After a period of $30 \mathrm{~min}$. (as in the case of Bialystok Glass Works) there is a change of direction (reversion) of air flow and combustion gases. The regenerator previously accumulating the heat is switched this time into the cooling cycle, while the other regenerator is reversed into the heating cycle. The regenerative matrix is made of innovative geometry ceramic bricks whose originality or novelty compared to the traditionally used shapes (i.e., closed rectangular shapes) are characterized by much thinner walls that considerably reduce matrix overheating thus creating better conditions for waste heat recovery. Furthermore, the shapes have some additional practical and operation advantages, namely they are easy to clean and show high resistance to corrosion and clogging up. Figure 2 show cross sections of individual tiles forming the regenerator matrix as used in the glass furnace working in Bialystok Glass Works. 


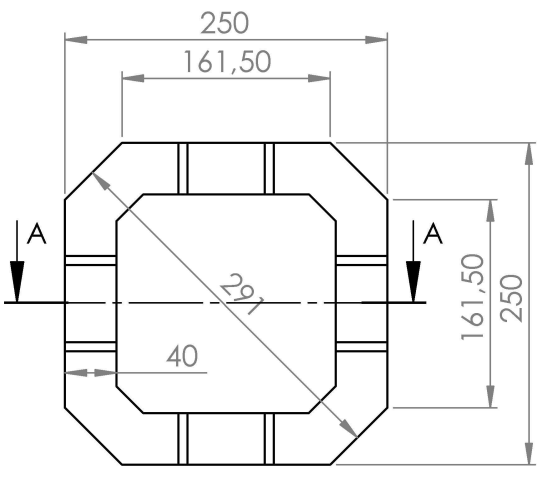

a)

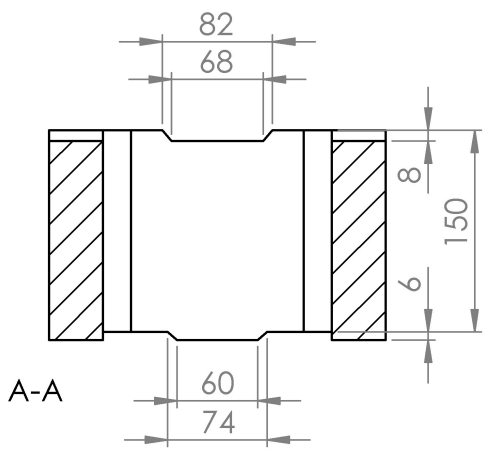

c)

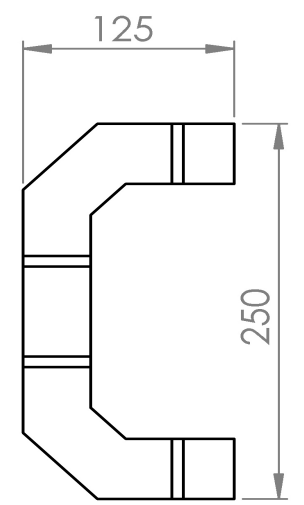

b)

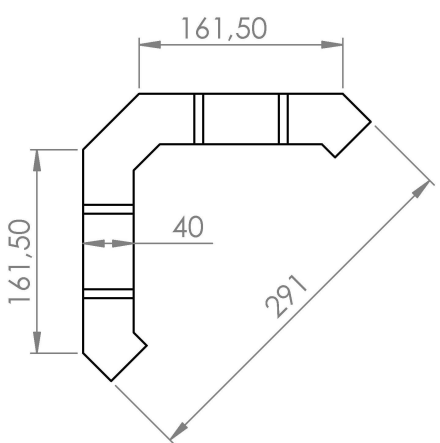

d)

Figure 2: Matrix bricks a) HS170, b) cross section HS170, c) 1/2 HS170, d) 4/8HS170.

A single matrix layer consists of forty-one HS170 bricks, one 4/8 HS170 brick and four $1 / 2$ HS170 bricks. The actual arrangement of individual bricks is illustrated in Fig. 3.

The regenerator matrix is made up of 29 layers of bricks loosely stacked so that one is laid on top of another to create a free flow of exhaust gas and air during operation. The total height of all the layers amounts to $4350 \mathrm{~mm}$. Each layer of the matrix is $150 \mathrm{~mm}$ high, while the two remaining dimensions, i.e., length and width are $2723 \mathrm{~mm} \times 2138 \mathrm{~mm}$, respectively. The individual layers differ in chemical composition which determines the ac- 


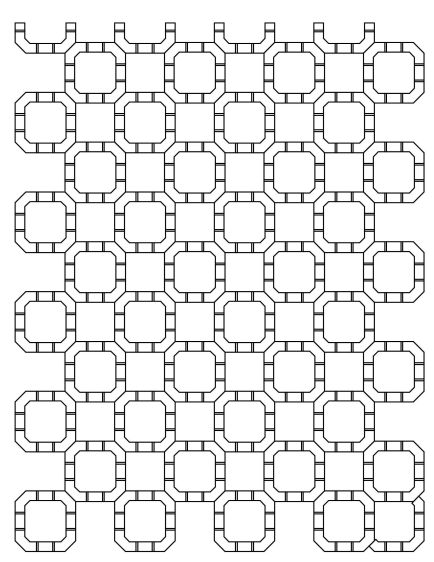

a)

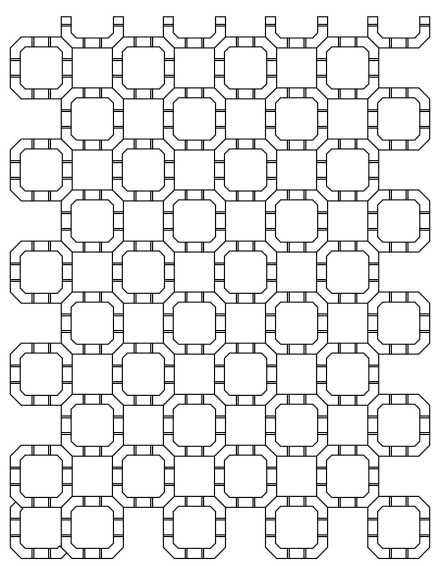

b)

Figure 3: Arrangement of matrix bricks: a) left regenerator, b) right regenerator.

tual the impact resistance of high temperature gases passing through the regenerator. The highest temperature region is composed of 5 layers of magnesia Glasmag bricks. Directly below, there are other 5 layers also made of magnesia Glasmag M96 with thermal properties similar to the previous ones. Underneath, there are 10 layers of Silimax KA silicate bricks whereas the bottom part is composed of 9 layers of Silimax KAB to suit the prevailing temperature conditions there. Table 1 shows the thermal properties of individual layers of regenerator matrix materials. The presented data come from the material product cards provided by the domestic producers, namely Ropczyce Magnesia Plant S.A. and Vesuvius Poland Sp. z o.o.. The layout of the bricks can be described with the following properties

- number of channels available for gas flow: 80 ;

- single channels height for gas flow along the regenerator from the inlet to exit: $4350 \mathrm{~mm}$;

- heat transfer area: $244 \mathrm{~m}^{2}$;

- heat storing mass: $17185 \mathrm{~kg}$. 
Table 1: Thermal properties of the matrix materials of the regenerator.

\begin{tabular}{|c|c|c|c|c|c|c|}
\hline No. & \multicolumn{2}{|c|}{ Property } & M98 & M96 & $\mathrm{KA}$ & KAB \\
\hline 1 & \multicolumn{2}{|c|}{ Mass density, $\mathrm{kg} / \mathrm{m}^{3}$} & 2920 & 2900 & 2530 & 2470 \\
\hline \multirow{7}{*}{2} & \multirow{7}{*}{$\begin{array}{c}\text { Specific heat } \\
{[\mathrm{kJ} / \mathrm{kg} \cdot \mathrm{K}]}\end{array}$} & $200^{\circ} \mathrm{C}$ & - & - & 0.991 & 0.992 \\
\hline & & $400^{\circ} \mathrm{C}$ & 1.08 & 1.08 & - & - \\
\hline & & $500^{\circ} \mathrm{C}$ & - & - & 1.141 & 1.142 \\
\hline & & $600^{\circ} \mathrm{C}$ & 1.18 & 1.18 & - & - \\
\hline & & $800^{\circ} \mathrm{C}$ & 1.26 & 1.26 & - & - \\
\hline & & $1000^{\circ} \mathrm{C}$ & 1.31 & 1.31 & - & - \\
\hline & & $1200^{\circ} \mathrm{C}$ & 1.37 & 1.37 & 1.243 & 1.244 \\
\hline \multirow{7}{*}{3} & \multirow{7}{*}{$\begin{array}{c}\text { Thermal } \\
\text { conductivity } \\
{[\mathrm{W} / \mathrm{m} \mathrm{K}]}\end{array}$} & $200^{\circ} \mathrm{C}$ & - & - & 2.41 & 2.23 \\
\hline & & $400^{\circ} \mathrm{C}$ & 4.48 & 4.48 & 2.26 & 2.08 \\
\hline & & $500^{\circ} \mathrm{C}$ & 3.48 & 3.48 & 2.22 & 2.04 \\
\hline & & $600^{\circ} \mathrm{C}$ & 2.72 & 2.72 & 2.24 & 2.07 \\
\hline & & $800^{\circ} \mathrm{C}$ & 2.32 & 2.32 & 2.30 & 2.15 \\
\hline & & $1000^{\circ} \mathrm{C}$ & 2.24 & 2.24 & - & - \\
\hline & & $1200^{\circ} \mathrm{C}$ & $9.43 \times 10^{-7}$ & $7.07 \times 10^{-7}$ & - & - \\
\hline
\end{tabular}

\subsection{Measuring equipment of the glass furnace and regenerators}

Temperature measurements of combustion gases and air in the regenerators were carried out using thermoelements and a laboratory thermometer. To read high temperature the simple head thermocouples were applied. They were fitted with ceramic 1XPtRh-Pt/S screens (top) and NiCr-NiAl/K screens (bottom) provided with a protective sheath $15 \mathrm{~mm}$ in diameter with no internal insulation. Maximum operation temperature was $1450{ }^{\circ} \mathrm{C}$, and the measurement error was $\pm 0.0075|t|$, where $t$ denotes the measurement temperature value. In the lower part of the regenerator a mercury thermometer was installed in order to measure the temperature of air supplied from outside. The amount of GZ50 natural gas supplied for combustion was read out from DY050 Yokogawa meter working within the measuring range $0-250 \mathrm{Nm}^{3} / \mathrm{h}$ with the measurement error $\pm 1 \%$. 


\section{Experimental determination of the regenerator effectiveness}

The effectiveness of a heat regenerator is defined as the ratio of the amount of heat exchanged in the regenerator either during the heating period or cooling period and the amount of heat that would be exchanged at the same inlet temperatures and heat capacity rates of the heat exchanging fluids in the countercurrent recuperator with a built-in infinitely large surface area for heat transfer [13].

The regenerators operate in a regular periodic manner, i.e., the regenerator matrix being heated for a given period, becomes subsequently subjected to cooling and vice versa. Then, for a regular periodical operation, the amount of heat $Q$ exchanged during the heating period in time range $\tau_{1}$ is balanced by the amount of heat transferred during the cooling period of the regenerator matrix in the time range $\tau_{2}$. Hence we have

$$
Q=\left(\dot{W}_{1} \tau_{1}\right)\left(\overline{t_{1}^{\prime}}-\overline{t_{1}^{\prime \prime}}\right)=\left(\dot{W}_{2} \tau_{2}\right)\left(\overline{t_{2}^{\prime \prime}}-\overline{t_{2}^{\prime}}\right),
$$

where $\dot{W}$ stands for gas heat capacity rates, $\overline{t^{\prime}}$ is the time average inlet gas temperature averaged over the inlet crossection) for the period, and $\overline{t^{\prime \prime}}$ is the time average outlet gas temperature (averaged over the outlet crossection) for the given period. The subscripts 1 and 2 stand for hot gas flow and air flow, respectively. The maximum amount of heat, $Q_{\max }$, is determined by the formula

$$
Q_{\max }=(\dot{W} \tau)_{\min }\left(\overline{t_{1}^{\prime}}-\overline{t_{2}^{\prime}}\right),
$$

where $(\dot{W} \tau)_{\min }$ is given as

$$
(\dot{W} \tau)_{\min }=\min \left[\dot{W}_{1} \tau_{1}, \dot{W}_{2} \tau_{2}\right] .
$$

Then regenerator effectiveness, $\varepsilon$, determined on the basis of the heating period is defined using the following formula:

$$
\varepsilon=\frac{Q}{Q_{\max }}=\frac{\left(\dot{W}_{1} \tau\right)\left(\overline{t_{1}^{\prime}}-\overline{t_{1}^{\prime \prime}}\right)}{(\dot{W} \tau)_{\min }\left(\overline{t_{1}^{\prime}}-\overline{t_{2}^{\prime}}\right)},
$$

while regenerator effectiveness determined on the basis of the cooling period is described as follows:

$$
\varepsilon=\frac{Q}{Q_{\max }}=\frac{\left(\dot{W}_{2} \tau\right)\left(\overline{t_{2}^{\prime \prime}}-\overline{t_{2}^{\prime}}\right)}{(\dot{W} \tau)_{\min }\left(\overline{t_{1}^{\prime}}-\overline{t_{2}^{\prime}}\right)} .
$$


For the investigated regenerators Eqs. (3) and (4) are used to experimentally determine the effectiveness. In most cases, as well as for the case considered here, the following inequality is satisfied $\dot{W}_{1} \tau_{1}>\dot{W}_{2} \tau_{2}$, and therefore we have $(\dot{W} \tau)_{\min }=\left(\dot{W}_{2} \tau_{2}\right)$, which reduces formula (4) to a simplified form, as follows:

$$
\varepsilon=\frac{\overline{t_{2}^{\prime \prime}}-\overline{t_{2}^{\prime}}}{\overline{t_{1}^{\prime}}-\overline{t_{2}^{\prime}}} .
$$

It must be noted here that in Eqs. (3) and (4) not only temperatures but also heat capacity rates of both the hot and cold gas, $\dot{W}_{1}$ and $\dot{W}_{2}$, are required. Thus, making use of the experimentally determined data of inlet and outlet gas temperatures (averaged as indicated above) as well as the corresponding heat capacity rates of each gas stream, we may find the regenerator effectiveness for each period.

\subsection{Average regenerator effectiveness}

Theoretically, the effectiveness values calculated from Eqs. (3) and (4) are equal since the heat balance given by Eq. (1) must be fulfilled. Hence, making use of the theoretical modeling only one effectiveness value referring to both periods simultaneously can be determined. However, when the effectiveness is determined using the experimental data measured for heating and cooling periods independently, the obtained values can differ by a fraction, which is due to the uncertainties in the measured data employed. As can be seen in Eq. (3), determining the effectiveness based on the heating period requires measuring (apart from the temperatures) the flow rates of the gas, the fact which considerably increases the uncertainties in effectiveness values for the heating period. On the other hand, determining the effectiveness with Eq. (5) requires, in fact, only three temperatures measured directly. Consequently, the accuracy of the effectiveness determined with this formula is significantly higher due to lower uncertainty. As a result, the data on the effectiveness of the regenerators presented below are determined as averaged by taking into account the effectiveness values for both periods as well as their corresponding uncertainties.

The averaging is performed as a weighted procedure according to the formulas presented in performance test codes (PTC 19.1-1998) [14]. Hence we obtain averaged effectiveness, $\varepsilon_{a v}$, expressed as

$$
\varepsilon_{a v}=w_{\Delta \varepsilon_{1}} \varepsilon_{1}+w_{\Delta \varepsilon_{2}} \varepsilon_{2},
$$


where $w_{\Delta \varepsilon_{1}}$ and $w_{\Delta \varepsilon_{2}}$ are the weights computed from uncertainties $\Delta \varepsilon_{1}$ and $\Delta \varepsilon_{2}$ in the effectiveness for heating and cooling periods, respectively as described by PTC 19.1-1998 [14]. The uncertainties $\Delta \varepsilon_{1}$ and $\Delta \varepsilon_{2}$ in the effectiveness for heating and cooling periods have been determined accordingly [15]. Thus we have the weights expressed as follows:

- for effectiveness $\varepsilon_{1}$ determined from the heating period

$$
w_{\Delta \varepsilon_{1}}=\frac{\Delta \varepsilon_{2}^{2}}{\Delta \varepsilon_{1}^{2}+\Delta \varepsilon_{2}^{2}},
$$

- for effectiveness $\varepsilon_{2}$ determined from the cooling period

$$
w_{\Delta \varepsilon_{2}}=\frac{\Delta \varepsilon_{1}^{2}}{\Delta \varepsilon_{1}^{2}+\Delta \varepsilon_{2}^{2}} .
$$

Thus, the uncertainty in the averaged effectiveness in Eq. (6) PTC $[14,15]$ is given as

$$
\Delta \varepsilon_{a v}=\sqrt{\left(w_{\Delta \varepsilon_{1}} \Delta \varepsilon_{1}\right)^{2}+\left(w_{\Delta \varepsilon_{2}} \Delta \varepsilon_{2}\right)^{2}} .
$$

The empirical effectiveness of the regenerators for particular periods has been determined using the experimental data recorded during the experiments. For each regenerator the number of readings in a single experimental run was 30 for either period. These data were used in all experiments referred to in the paper. It is worth to note that all the uncertainties of the properties measured directly as well as indirectly were computed using the methodology described in [16]. Thus uncertainty $\delta_{\bar{y}}$ referring to mean value $\bar{y}$ of directly measured property $y$ (in this case referring to both temperatures of the hot gas cooled and cold air heated, as well as the data on the flue gas analysis and also flow rates of natural gas) takes into account not only systematic but also random error contributions. Hence we have

$$
\delta_{\bar{y}}=\sqrt{\sum \delta_{s}^{2}+\left(2 \delta_{r}\right)^{2}},
$$

where particular systematic errors should be known a priori, also including the errors due to calibration, acquisition system, spatial no uniformity, or faulty installation. Having determined $\delta_{\bar{y}}$ from Eq. (10), directly measured property $y$ is given as

$$
y=\bar{y} \pm \delta_{\bar{y}} .
$$

However, uncertainty $\delta_{z}$ in indirectly measured property $z$ in this case referring to regenerator effectiveness for particular periods, mass flow rates 
of heated as well as cooled gas streams, excess air factor, and also volumes of particular components of the particular gas components) is described by

$$
\delta_{z}=\sqrt{\sum_{k}\left(\frac{\partial z}{\partial y_{k}} \delta y_{k}\right)^{2}},
$$

where property $z$ is dependent on a number of directly measured properties $y_{k}$ each of which is determined at uncertainty $\delta_{y_{k}}$ according to Eq. (10).

We also should note here that all the experiments were performed at about the same mass flow rate of natural gas used as burnt fuel for the furnace. This was due to the necessity of maintaining constant operational parameters of the furnace in order to ensure satisfactory quality of the molten glass.

\section{Experimental results on regenerator effectiveness}

The final experimental results are presented in Tab. 2 and refer to the effectiveness determined experimentally on the basis of the data measured independently for each heating and cooling period. As seen, the effectiveness values for the heating period in comparison with the cooling one differ by a fraction due to the uncertainties in measured properties used with Eqs. (3) and (5). Also the values of the averaged effectiveness in Eq. (6) of are presented with their corresponding uncertainties computed using Eqs. (7)-(9).

\section{Concluding remarks}

The effectiveness of fixed matrix regenerators employed with an industrial scale glass melting furnace has been considered. The values of the effectiveness have been determined experimentally using the data acquired for both cooling and heating periods. Furthermore, a detailed description of experimental methodology, the measuring instruments used, as well as data reduction procedure and uncertainty analysis are presented. Also the furnace as well as regenerators are described together with the thermal properties of refractory bricks used for the regenerator construction. Averaged effectiveness data for both the heating and cooling periods including the corresponding uncertainties have been presented. Finally, it is worth 
Table 2: Experimental effectiveness of the regenerators.

\begin{tabular}{|c|c|c|c|c|c|c|c|}
\hline No. & Period & Regenerator & $\begin{array}{c}\text { Natural gas } \\
\text { flow } \pm \\
\text { uncertainty, } \mathrm{Nm}^{3} / \mathrm{s}\end{array}$ & $\begin{array}{c}\text { Average temp. of } \\
\text { flue gas/air top/ } \\
\text { bottom } \pm \\
\text { uncertainty, },{ }^{\circ} \mathrm{C} \\
\end{array}$ & $\begin{array}{c}\text { Mass flow } \\
\text { air/gas } \pm \\
\text { uncertainty, } \mathrm{kg} / \mathrm{s}\end{array}$ & $\begin{array}{c}\text { Effectiveness } \\
\pm \\
\text { uncertainty }\end{array}$ & $\begin{array}{c}\text { Average } \\
\text { effectiveness } \pm \\
\text { uncertainty }\end{array}$ \\
\hline \multirow{3}{*}{1} & cooling & left & $0.0369 \pm 3.69 \times 10^{-4}$ & $\begin{array}{c}1178 \pm 26.9 \\
233 \pm 26.1\end{array}$ & $0.5266 \pm 9.08 \times 10^{-3}$ & $\begin{array}{l}0.9444 \pm \\
0.0377\end{array}$ & \multirow{3}{*}{$\begin{array}{c}0.9400 \pm \\
0.0340\end{array}$} \\
\hline & \multirow{2}{*}{ heating } & \multirow{2}{*}{ left } & \multirow{2}{*}{$0.0369 \pm 3.69 \times 10^{-4}$} & $1245 \pm 28.0$ & \multirow{2}{*}{$0.5563 \pm 4.22 \times 10^{-2}$} & $0.9206 \pm$ & \\
\hline & & & & $518 \pm 26.3$ & & 0.0783 & \\
\hline \multirow{3}{*}{2} & cooling & right & $0.0369 \pm 3.69 \times 10^{-4}$ & $1192 \pm 26.5$ & $0.5266 \pm 6.49 \times 10^{-3}$ & $0.9438 \pm$ & \multirow{3}{*}{$\begin{array}{c}0.8987 \pm \\
0.0341\end{array}$} \\
\hline & \multirow{2}{*}{ heating } & \multirow{2}{*}{ right } & \multirow{2}{*}{$0.0369 \pm 3.69 \times 10^{-4}$} & $\frac{303 \pm 26.1}{1234 \pm 28.0}$ & \multirow{2}{*}{$0.5563 \pm 3.02 \times 10^{-2}$} & $\frac{0.0400}{0.7785 \pm}$ & \\
\hline & & & & $583 \pm 26.4$ & & 0.0653 & \\
\hline \multirow{3}{*}{3} & \multirow{2}{*}{ cooling } & \multirow{2}{*}{ left } & \multirow{2}{*}{$0.0231 \pm 2.31 \times 10^{-4}$} & $1179 \pm 26.9$ & \multirow{2}{*}{$0.3286 \pm 9.30 \times 10^{-3}$} & $0.9445 \pm$ & \multirow{3}{*}{$\begin{array}{c}0.9420 \pm \\
0.0336\end{array}$} \\
\hline & & & & $230 \pm 26.1$ & & 0.0376 & \\
\hline & heating & left & $0.0231 \pm 2.31 v 10^{-4}$ & $1245 \pm 28.2$ & $0.3493 \pm 4.28 \times 10^{-2}$ & $0.9317 \pm$ & \\
\hline \multirow{3}{*}{4} & \multirow[b]{2}{*}{ cooling } & \multirow[b]{2}{*}{ right } & \multirow{2}{*}{$0.0231 \pm 2.31 \times 10^{-4}$} & $1193 \pm 26.5$ & \multirow[b]{2}{*}{$0.3286 \pm 6.61$} & $0.9443 \pm$ & \multirow{3}{*}{$\begin{array}{c}0.9038 \pm \\
0.0345\end{array}$} \\
\hline & & & & $304 \pm 26.1$ & & 0.0400 & \\
\hline & heating & right & $0.0231 \pm 2.31 \times 10^{-4}$ & $\begin{array}{l}1235 \pm 25.1 \\
230+261\end{array}$ & $0.3493 \pm 3.04 \times 10^{-2}$ & $0.7854 \pm$ & \\
\hline
\end{tabular}

emphasizing that real scale regenerators are normally constructed using ceramics elements whose refractory properties differ over the regenerator's height. This is done to better adapt the regenerators to different temperature conditions in which they operate. In turn, thermal properties of the regenerator matrix can vary considerably depending on the gas temperature along the flow. As a result, any theoretical modeling of energy transfer processes for high temperature thermal regenerators accounting for both gas and matrix constant properties may result in poorer accuracy of the final outcomes.

Received 23 June 2015

\section{References}

[1] Hausen H.: Über die Theorie des Wärmeaustausches in Regeneratoren. Zeitschrift für angewandte Mathematik und Mechanik 9(1929), 173-200.

[2] Nusselt W.: Die Theorie des Winderhitzers. Zeitschrift des Vereines deutscher Ingenieure 71(1927), 3, 85-91.

[3] Willmot A.J.: The regenerative heat exchanger computer representation. Int. J. Heat Mass Trans. 12(1969), 9, 997-1014.

[4] Bes T.M.: Energiespeichervermögen eines periodisch erwärmten und gekühlten Festkörpers. Bull. De L'Académie Polonaise des Sciences. Serie des Sciences Techniques 17(1969), 1, 5-13.

[5] Szargut J.: Numerical methods in thermal calculations of industrial furnaces. Silesia Publishers, Katowice 1977. 
[6] Romie F., BACLIC B.S.: Methods for rapid calculation of the operation of asymmetric coucterflow regenerators. J Heat Trans-T ASME 110(1988) 785-788.

[7] Yu J., Zhang M., Fan W., Zhou Y., Zhao G.: Study on performance of the ball packed-bed regenerator: experiments and simulation. Appl. Therm. Eng. 22(2002), 641-651.

[8] Zarrinehkafsh M.T., Sadrameli S.M.: Simulation of fixed bed regenerative heat exchangers for flue gas heat recovery. Appl. Therm. Eng. 24(2004). 373-382.

[9] Reboussin Y., Fourmigue J.F., Marty P., Citti O.: A numerical approach for the study of glass furnace regenerators. Appl. Therm. Eng., 25(2005), 2299-320.

[10] WoŁKOWYCKI G.: Experimental results on the fixed matrix regenerator effectiveness for a glass stove furnace. Heat Transfer Eng. 37(2015), 6 , 591-602.

[11] Sardeshpande V., Anthony R., Gaitonde U.N., Banerjee R.: Performance analysis for glass furnace regenerator. Appl. Energ. 88(2011), 4451-4458.

[12] Schack A.: Industrial Heat Transfer: Practical and Theoretical with Basic Numerical Examples. John Wily, New York 1965.

[13] Skiepko T., Shah R.K.: Modeling and effect of leak-ages on heat transfer performance of fixed matrix regenerators. Int. J. Heat Mass Tran. 48 (2005), 1608-1632.

[14] An American National Standard, ASME PTC 19.1-1998, Test Uncertainty, Instruments and Apparatus. ASME, 1998.

[15] Lestina T., ScotT B.: Assessing the uncertainty of thermal performance measurements of industrial heat exchangers. In: Compact Heat Exchangers for the Process Industries. Proc. Int. Conf. on Compact Heat Exchangers for the Process Industries, held at the Cliff Lodge and Conference Center, Snowbird, Utah, June 22-27, 1997, 401-416.

[16] Moffat R.J.: Describing the uncertainties in experimental results. Exp. Therm. Fluid Sci. 1(1988), 3-17. 